\title{
A COMUNICAÇÃO NÃO-VERBAL ENTRE PROFESSORES DE EDUCAÇÃO ESPPECIAL E PAIS DE CRIANÇAS/JOVENS COM NECESSIDADES EDUCATIVAS ESPECIAIS
}

\author{
Lurdes Cardoso ${ }^{1}$ \\ Cristina Simões ${ }^{2}$
}

\begin{abstract}
RESUMO: O presente estudo tem por objetivo conhecer o papel que a comunicação não-verbal (CNV) desempenha na comunicação interpessoal entre o professor de educação especial e os pais de crianças/jovens com Necessidades Educativas Especiais (NEE).

Relativamente ao estudo empírico selecionámos, de forma aleatória, vinte professores de educação especial do concelho de Viseu. $O$ instrumento aplicado para a recolha de dados foi um questionário que elaboramos a partir da revisão da literatura.

A análise dos resultados permitiu clarificar que o papel da CNV é de importância capital, pois fornece ao professor de educação especial inúmeras informações que os pais de crianças/jovens com NEE têm, por vezes, receio em verbalizar. Por outro lado, da parte do professor de educação especial existe a perceção que a utilização desta ferramenta potencia a criação de um ambiente de confiança e empatia, devolvendo a estes pais um sentimento de autonomia, competência e dignidade. Nesta conformidade, a CNV pode contribuir para um melhor relacionamento interpessoal entre o professor de educação especial e os pais de crianças/jovens com NEE.
\end{abstract}

Palavras-chave: comunicação não-verbal; relação interpessoal; professor de educação especial; pais de crianças/jovens com NEE

ABSTRACT: The present study aims to know the role which the non-verbal communication plays in the interpersonal communication between the special needs teacher and the parents of children lyoung people with learning disabilities.

\footnotetext{
${ }^{1}$ Professora de Inglês

2 Professora de Educação Especial no Agrupamento de Escolas de Tondela, Doutoranda em Ciências da Educação, em Educação Especial. E-mail: cristinaferreira@iol.pt
} 
Concerning the empirical study, we have selected, at random, twenty special needs teachers from Viseu city council. The applied instrument to collect the information we needed, was a questionnaire we built from the literature revision. The information result allowed us to clarify that the role of non-verbal communication plays a capital importance, because it allows the special needs teacher to get a lot of information from parents with learning disabilities' children lyoung people, who sometimes are afraid to express themselves. On the other hand, it seems that, for the special needs teacher, the use of this tool creates a more confidence and empathy environment that gives a feeling of autonomy, competence and dignity to these parents. In general, we concluded, that non-verbal communication contributes for a better interpersonal relation between the special needs teacher and the parents of children /young people with learning disabilities.

Keywords: non-verbal communication; interpersonal relation; special needs teacher; parents of children /young people with learning disabilities.

\section{INTRODUÇÃO}

O reconhecimento de que os pais de crianças/jovens com NEE são uma constante e um pilar na vida dos mesmos, antes, durante e após a escolaridade, deve levar o professor de educação especial a reforçar o envolvimento, bem como as competências destas famílias, pois só respondendo às necessidades dos pais é que estes podem responder às necessidades dos filhos. Neste contexto e segundo Correia (2003), os serviços de educação especial são um fim essencial, pois servem para tentar prevenir, reduzir ou suprimir a problemática de um aluno com NEE minimizando, desta forma, o stress das famílias.

Tendo em conta o que o atual enquadramento legal da educação especial determina o envolvimento efetivo dos encarregados de educação, quer no processo de avaliação, quer na elaboração do programa educativo individual (PEI), parece-nos pertinente que ao nível dos agrupamentos de escolas e sobretudo dos docentes se espelhe esta legislação, intensificando as formas de comunicação e de colaboração com as famílias.

O conhecimento das características dos pais de crianças/jovens com NEE, o seu percurso bem como as suas relações interpessoais são determinantes de forma a se poderem elaborar intervenções individuais e sistemáticas para com os seus filhos. A relação entre o professor de educação especial e os pais implica uma abordagem rigorosa, afetiva e individualizada, já que estas famílias apresentam características muito próprias. Desta forma, a importância da comunicação, sobretudo a CNV, que apela mais à parte afetiva e emotiva, é imprescindível para se poder 
responder às características e necessidades de cada família com crianças/jovens com NEE.

As necessidades destas famílias são de vária ordem, entre as quais destacamos: socialização, identidade pessoal, apoio afetivo-emocional e educativas (McWilliam, 2003; Cruz, 2005; Dunst \& Dempsey, 2007; Correia, 2008; Alves 2009, Pereira \& Serrano, 2010). Torna-se, assim, essencial ajudar os pais de crianças/jovens com NEE a desenvolver uma identidade pessoal positiva, de forma a obterem uma qualidade de vida emocionalmente satisfatória, para poderem auxiliar os seus filhos nas diferentes etapas da sua vida.

Nesta conformidade, a inclusão dos alunos com NEE, nas escolas do ensino regular deve ser fruto da conjugação dos esforços dos professores e das famílias pois, de acordo com Rodrigues (2006), "a educação inclusiva pressupõe uma participação plena numa estrutura em que os valores e práticas são delineados tendo em conta todas as características, interesses, objetivos e práticas de todos os participantes no ato educativo" (p. 77). Neste contexto, cabe à comunidade educativa criar as condições necessárias para dar as mesmas oportunidades a todos os alunos, independentemente das diferenças de cada um (Leitão, 2007).

$\mathrm{Na}$ base deste envolvimento facilmente se depreende o papel da comunicação, que é a base da relação humana. A comunicação de que falamos envolve muito mais do que palavras, envolve sentimentos e emoções, envolve crenças e opiniões, envolve convicção, envolve poder e submissão, envolve competência, proximidade ou constrangimento, entre muitas outras.

Assim, a preocupação em compreender todos os sistemas que movem a CNV entre o profissional de educação especial e os pais de crianças/jovens com NEE levou-nos a explorar vários olhares sobre a temática, de forma a percebermos a sua importância na construção de uma relação interpessoal de empatia.

A comunicação é uma necessidade humana básica. Quando nascemos não sabemos falar uma língua, no entanto, conseguimos comunicar. Esta é importante para o nosso crescimento enquanto seres humanos, pois faz parte das nossas experiências anteriores e daquelas adquiridas no nosso dia-a-dia (Davis, 1979; Dortier, 2001). É também determinante para estabelecermos vínculos afetivos, sociais e profissionais com as pessoas que nos rodeiam (Fritzen, 1987; Antunes, 2003; Gabin \& Dortier, 2008, Mucchielli, 2009). A comunicação é uma forma de interação social propositada, quando se dão demonstrações de apresentação pessoal, combinadas ou não com casos de (re)construção de conhecimento e troca de informações (Almeida, 2008). Ainda segundo o mesmo autor, "para 
nos entendermos negociamos sentidos, ou seja, trocamos ideias" (pp. 89).

É através da comunicação interpessoal que criamos as relações sociais, pois toda a interação tem um sentido emocional implícito. Falar com outra pessoa é um processo dinâmico, na medida em que quando comunicamos, a outra pessoa reage e a sua reação influencia as nossas reações subsequentes (Goleman, 2010).

É indiscutível que a comunicação é fundamental para qualquer ser humano. Desta forma, o domínio da comunicação interpessoal, pelas suas características, é determinante, sobretudo na relação entre o professor de educação especial e os pais. Transportando esta relação para um contexto de atendimento a pais de crianças/jovens com NEE, os professores e os pais também interagem sob influência da realidade de cada um. Assim, quando um professor comunica com um pai, todo o processo comunicativo entre eles está a ser influenciado pela realidade que cada um conhece do outro, como por exemplo a família de cada um, a linguagem que utilizam, as suas postura, as constituições físicas, entre outros aspetos (Serrano \& Correia, 2003; Mcwilliam, 2003; Pimentel, 2005). O controlo deste tipo de comunicação permite um maior sucesso nos relacionamentos entre professores/pais, pois o interesse por parte do profissional de educação especial reflete a sua capacidade de compaixão, disponibilidade e sensibilidade. Segundo Correia (2008) toda a relação existente no atendimento aos pais de crianças/jovens com NEE depende, em grande parte, das capacidades comunicativas dominadas pelo professor.

Porque raramente as emoções são traduzidas em palavras, a chave para as intuirmos reside na habilidade de as lermos através de canais nãoverbais. Segundo Richmond e colaboradores (2011) nos últimos vinte anos houve um grande aumento no número de pesquisas que envolvem a CNV. Os autores acreditam que é tão importante quanto a comunicação verbal para um bom relacionamento interpessoal.

Para Burgoon e colaboradores $(2010$, p. 6) "a comunicação não-verbal é um código elaborado que não está escrito em lugar nenhum, desconhecido por todos, mas por todos entendido". Neste sentido, a CNV não deve ser tratada como um fenómeno isolado, mas sim como parte integrante da comunicação como um todo, pois, o Homem não começou o seu ciclo comunicativo através do sistema verbal, uma vez que a aprendizagem de uma língua materna é um processo demorado e que exige alguma maturação (Manusov, 2005; Leathers \& Eaves, 2008; Moore, et al., 2010; Richmond et al., 2011). Todavia, sempre foi capaz de comunicar, nomeadamente através de gestos, posturas, posicionamentos, entre outros. Na mesma linha de pensamento, Leathers e Eaves (2008) 
afirmam que a comunicação gestual é anterior à utilização de signos falados e, em muitos casos, esta serve para dar início à interação.

Neste sentido, a CNV tem um peso substancial em toda a interação. A linguagem não-verbal, para além de ser tão ou mais eficaz no ato comunicativo, assume um papel indiscutivelmente dominante no que diz respeito ao sentido (Burgoon et al., 2010). Nesta sequência, os mesmos autores, referem, que "menos de trinta e cinco por cento do significado social de uma situação é transmitida verbalmente" (p. 4). Para Axtell (2007) noventa por cento das nossas emoções são expressas de forma não-verbal. Estas percentagens levam-nos, inevitavelmente, à pertinência do nosso estudo relativamente ao uso da CNV.

Nesta conformidade, surge-nos a seguinte pergunta de partida norteadora do nosso estudo: qual a importância que desempenha a CNV na criação de uma relação interpessoal entre o professor de educação especial e os pais de crianças/jovens com NEE?

\section{OBJETIVOS DO ESTUDO}

O grande objetivo desta investigação é verificar qual a importância da CNV na criação de uma relação interpessoal entre o professor de educação especial e os pais de crianças/jovens com NEE. Para atingir tal prepósito, tivemos em linha de conta outros objetivos específicos que nos ajudarão a especificar o objeto de análise.

Assim, pretendemos:

- Conhecer qual a perceção dos professores de educação especial face à construção de relações interpessoais com os pais de crianças/jovens com NEE;

- Identificar que conhecimentos têm os professores de educação especial sobre os principais sistemas da CNV;

- Verificar de que modo é que os professores valorizam e interpretam a CNV dos pais de crianças/jovens com NEE;

- Verificar qual a importância da CNV atribuída pelos professores de educação especial na relação que estabelecem com os pais de crianças/jovens com NEE.

\section{PROCEDIMENTOS METODOLÓGICOS}

A investigação que desenvolvemos insere-se numa abordagem do tipo quantitativo e descritivo, de forma a analisar uma realidade, pela utilização da técnica de análise de dados, recolhidos através de opiniões 
manifestadas num inquérito por questionário. Esta metodologia permite analisar a realidade nas suas variáveis orgânicas e nas suas relações com o que o rodeia, tendo por finalidade contribuir para o desenvolvimento e validação dos conhecimentos (Dias, 2009; Vaz Freixo, 2011).

Na perspetiva de Afonso (2005), este é um tipo de investigação que se preocupa com uma recolha fiável e sistemática dos dados através de procedimentos empíricos com o objetivo de generalizar e interrelacionar conceitos que permitem traduzir essa realidade. Ainda de acordo com o mesmo autor, os estudos naturalistas primam por uma pesquisa de situações reais e identificáveis pelo investigador, sem interferência do mesmo. Tal distanciamento do investigador torna-se numa mais-valia em relação a sua capacidade para questionar a realidade bem como de a divulgar (Afonso, 2005; Dias, 2009; Vaz Freixo, 2011).

Para fazermos um levantamento do que os professores de educação especial sabem acerca da CNV e da sua importância na criação de uma relação interpessoal mais empática com os pais de crianças/jovens com NEE, optámos por um método naturalista, procedendo-se à recolha de dados com recurso a um questionário. Segundo Quivy e Campenhoudt (2003), o questionário é uma técnica precisa que se adequa particularmente bem a uma utilização pedagógica, dando possibilidade de quantificar uma multiplicidade de dados e proceder a numerosas análises. Nesta mesma linha de pensamento, Tuckman (2002) afirma que os questionários são processos para adquirir dados sobre as pessoas.

O questionário foi elaborado e reestruturado em função da informação que pretendíamos obter, assim como a amostra a que se destinava. Nesta conformidade, os questionários foram entregues a 20 professores de educação especial, de várias escolas do concelho de Viseu.

Após a receção dos questionários, a informação contida nos itens de resposta foi digitada e tratada informaticamente no programa Excel. De seguida procedemos à computação de frequências e percentagens das várias alternativas de respostas. Relativamente às perguntas de resposta aberta, procedeu-se à sua categorização e análise de conteúdo que, de acordo com Bardin (2011), traduzem a informação recolhida em dados que possam ser tratados qualitativamente.

\section{APRESENTAÇÃO DOS RESULTADOS}

O nosso estudo teve por base uma análise quantitativa e qualitativa do que os docentes de educação especial conhecem acerca da CNV. 


\section{Quadro I}

Estratégias de comunicação para estabelecer uma relação empática com os pais de crianças/jovens com NEE

\begin{tabular}{|l|l|c|c|}
\hline \multicolumn{1}{c|}{ Categoria } & \multicolumn{1}{|c|}{ Subcategorias } & n & $\%$ \\
\hline & $\begin{array}{l}\text { Conhecimento da problemática dos alunos com } \\
\text { NEE }\end{array}$ & 4 & $13 \%$ \\
\cline { 2 - 4 } & $\begin{array}{l}\text { Mostrar interesse pela problemática dos alunos } \\
\text { com NEE }\end{array}$ & 4 & $13 \%$ \\
\hline $\begin{array}{l}\text { Estratégias de } \\
\text { comunicação } \\
\text { para } \\
\text { estabelecer } \\
\text { uma relação } \\
\text { empática com } \\
\text { os pais }\end{array}$ & Conhecer as respostas existentes & 2 & $6 \%$ \\
\cline { 2 - 4 } & Ganhar a confiança dos pais & 1 & $3 \%$ \\
\cline { 2 - 5 } & Deixar os pais expressarem-se livremente & 7 & $23 \%$ \\
\cline { 2 - 5 } & Escuta ativa & 2 & $6 \%$ \\
\cline { 2 - 5 } & Cuidar da postura & 7 & $23 \%$ \\
\cline { 2 - 5 } & Ajudar os pais & 1 & $6 \%$ \\
\hline & Não respondeu & 31 & $100 \%$ \\
\hline
\end{tabular}

No quadro I, a questão era de natureza aberta, através da qual se pretendia saber qual a opinião dos participantes acerca das estratégias de comunicação para estabelecerem uma relação empática com os pais. Desta categoria emergiram 9 subcategorias, sendo as mais significativas "Deixar os pais expressarem-se livremente" ( $\mathrm{n}=7 ; 23 \%)$; a "Escuta ativa" $(\mathrm{n}=7 ; 23 \%)$; o "Conhecimento da problemática dos alunos com NEE" $(\mathrm{n}=4 ; 13 \%)$ e o "Mostrar interesse pela problemática dos alunos com NEE" $(\mathrm{n}=4 ; 13 \%)$.

\section{Quadro II}

Sistemas de CNV mais conhecidos pelos docentes de educação especial

\begin{tabular}{|l|c|c|}
\hline \multicolumn{1}{|c|}{ Sistemas de CNV } & n & \% \\
\hline Paralinguagem & 12 & $10 \%$ \\
\hline A cinésica & 10 & $9 \%$ \\
\hline Gestos & 16 & $14 \%$ \\
\hline Expressão facial & 19 & $16 \%$ \\
\hline Sorriso & 13 & $11 \%$ \\
\hline Contacto visual & 19 & $16 \%$ \\
\hline Postura & 15 & $13 \%$ \\
\hline Tato & 6 & $5 \%$ \\
\hline Proxêmica & 4 & $3 \%$ \\
\hline Aparência física & 5 & $4 \%$ \\
\hline Não respondeu & 1 & $1 \%$ \\
\hline Total & 20 & $100 \%$ \\
\hline
\end{tabular}


No quadro II, quanto aos sistemas de CNV apurou-se que, na amostra em estudo, quase todos os docentes afirmaram conhecer uma variedade destes sistemas, sendo os mais conhecidos os seguintes: a expressão facial, o contacto visual, ambos com o mesmo número de respostas $(\mathrm{n}=19 ; 16 \%)$. Depois surgem os gestos $(\mathrm{n}=16 ; 14 \%)$; a postura $(\mathrm{n}=15$; $13 \%)$; o sorriso $(\mathrm{n}=13 ; 11 \%)$, a paralinguagem $(\mathrm{n}=12 ; 10 \%)$; a cinésica $(\mathrm{n}=10 ; 9 \%) ; \mathrm{o}$ tato $(\mathrm{n}=6 ; 5 \%)$; a aparência física $(\mathrm{n}=5 ; 4 \%)$; e a proxêmica $(\mathrm{n}=4 ; 3 \%)$.

\section{Quadro III}

Importância atribuída aos sinais não-verbais que os pais de crianças/jovens com NEE emitem

\begin{tabular}{|l|c|c|}
\hline $\begin{array}{l}\text { Importância atribuída aos sinais não-verbais } \\
\text { emitidos pelos pais de crianças/jovens com NEE }\end{array}$ & $\mathbf{n}$ & $\%$ \\
\hline Nenhuma & 0 & $0 \%$ \\
\hline Pouca & 1 & $5 \%$ \\
\hline Alguma & 6 & $30 \%$ \\
\hline Muita & 10 & $50 \%$ \\
\hline Toda & 1 & $5 \%$ \\
\hline Não respondeu & 2 & $10 \%$ \\
\hline Total & 20 & 100 \\
\hline
\end{tabular}

No quadro III, no que se refere à importância atribuída pelos sujeitos da amostra aos sinais não-verbais que os pais de crianças/jovens com NEE emitem, verificou-se que a maioria $(\mathrm{n}=10 ; 50 \%)$ atribui muita importância; seguidos dos docentes que admitiram alguma importância $(n=6 ; 30 \%)$. Apenas um docente diz que os sinais não-verbais têm toda a importância $(\mathrm{n}=1 ; 5 \%)$.

No quadro IV, quanto aos sinais não-verbais emitidos pelos pais de crianças/jovens com NEE, apurou-se que, os docentes de educação especial dão especial atenção à expressão facial (n=16; 20\%), seguida dos gestos e do contacto visual, ambos com o mesmo número de respostas $(\mathrm{n}=13 ; 17 \%)$. Depois surge a postura $(\mathrm{n}=12 ; 15 \%)$; a paralinguagem $(\mathrm{n}=10 ; 13 \%)$; o sorriso $(\mathrm{n}=7 ; 9 \%)$; a cinésica $(\mathrm{n}=5 ; 6 \%)$ e a aparência física $(\mathrm{n}=1 ; 1 \%)$. $\mathrm{O}$ tato e a proxêmica não foram referidos pelos participantes, tendo havido ainda um inquirido que não respondeu a esta questão $(\mathrm{n}=1 ; 1 \%)$. 


\section{Quadro IV}

Perceção dos sinais não-verbais mais comuns emitidos pelos pais de crianças/jovens com NEE

\begin{tabular}{|l|c|c|}
\hline $\begin{array}{l}\text { Sinais não-verbais mais comuns emitidos pelos } \\
\text { pais de crianças/jovens com NEE }\end{array}$ & $\mathbf{n}$ & $\mathbf{\%}$ \\
\hline Paralinguagem & 10 & $13 \%$ \\
\hline A Cinésica & 5 & $6 \%$ \\
\hline Gestos & 13 & $17 \%$ \\
\hline Expressão facial & 16 & $20 \%$ \\
\hline Sorriso & 7 & $9 \%$ \\
\hline Contacto visual & 13 & $17 \%$ \\
\hline Postura & 12 & $15 \%$ \\
\hline Tato & 0 & $0 \%$ \\
\hline Proxêmica & 0 & $0 \%$ \\
\hline Aparência física & 1 & $1 \%$ \\
\hline Não respondeu & 1 & $1 \%$ \\
\hline Total & 78 & 100 \\
\hline
\end{tabular}

Quadro V

Sinais não-verbais influenciadores da relação estabelecida com os pais de crianças/jovens com NEE

\begin{tabular}{|l|l|c|c|}
\hline \multicolumn{1}{c|}{ Categoria } & \multicolumn{1}{c|}{ Subcategorias } & n & $\%$ \\
\hline \multirow{2}{*}{$\begin{array}{l}\text { Sinais não- } \\
\text { verbais } \\
\text { influenciadores } \\
\text { da relação } \\
\text { estabelecida } \\
\text { com os pais de } \\
\text { crianças/jovens } \\
\text { com NEE }\end{array}$} & Depende da pessoa em questão & 1 & $2 \%$ \\
\cline { 2 - 4 } & Expressão facial & 7 & $15 \%$ \\
\cline { 2 - 4 } & Cestos & 4 & $9 \%$ \\
\cline { 2 - 4 } & Pontacto visual & 11 & $24 \%$ \\
\cline { 2 - 4 } & Sorriso & 13 & $28 \%$ \\
\cline { 2 - 5 } & Não respondeu & 7 & $15 \%$ \\
\hline & Total & 2 & $4 \%$ \\
\cline { 2 - 5 } & & 46 & 100 \\
\hline
\end{tabular}

Através dos resultados expostos no quadro V, relativo aos "Sinais não-verbais influenciadores da relação estabelecida com os pais de crianças/jovens com NEE", emergiram 7 subcategorias, das quais sobressaíram as seguintes: a "Postura" ( $\mathrm{n}=13 ; 28 \%)$; o "Contacto visual" (n=11; 24\%); a "Expressão facial" ( $\mathrm{n}=7 ; 15 \%)$; o "Sorriso" $(\mathrm{n}=7 ; 15 \%)$ e os "Gestos" (n=4; 9\%). 


\section{Quadro VI}

Forma de estimular a CNV com os pais de crianças/jovens com NEE

\begin{tabular}{|l|l|c|c|}
\hline Categoria & \multicolumn{1}{|c|}{ Subcategorias } & n & $\%$ \\
\hline \multirow{4}{*}{$\begin{array}{l}\text { Modo para } \\
\text { estimular a } \\
\text { comunicação } \\
\text { não-verbal } \\
\text { com os pais de } \\
\text { crianças/jovens } \\
\text { com NEE }\end{array}$} & Depende da pessoa em questão & 6 & $21 \%$ \\
\cline { 2 - 4 } & Olhá-los nos olhos & 6 & $21 \%$ \\
\cline { 2 - 4 } & Ouvi-los com atenção & 1 & $4 \%$ \\
\cline { 2 - 4 } & Deixá-los falar & 1 & $4 \%$ \\
\cline { 2 - 4 } & Semonstrabelecer carinho pelos filhos & 1 & $4 \%$ \\
\cline { 2 - 4 } & Sorrir-lhes & 6 & $21 \%$ \\
\hline & Tão respondeu & 2 & $7 \%$ \\
\hline & Total & 28 & $18 \%$ \\
\hline
\end{tabular}

Os dados apresentados no quadro VI referem-se à questão aberta "Qual a opinião dos professores acerca da forma como podem estimular a comunicação não-verbal com os pais de crianças/jovens com NEE". Assim, desta categoria apuraram-se 7 subcategorias, sendo as mais significativas as seguintes: "Depende da pessoa em questão" $(\mathrm{n}=6 ; 21 \%)$, "Olhá-los nos olhos" ( $\mathrm{n}=6 ; 21 \%)$; "Estabelecer uma aproximação física" $(\mathrm{n}=6 ; 21 \%)$, todas com o mesmo número de resposta $(\mathrm{n}=6 ; 21 \%)$. Há a considerar a opinião de dois sujeitos da amostra, $(n=2 ; 7 \%)$ os quais referiram o "sorrir para os pais de crianças/jovens com NEE".

\section{Gráfico I}

Opinião dos docentes sobre o facto de a CNV contribuir para uma relação interpessoal de empatia com os pais de crianças/jovens com NEE

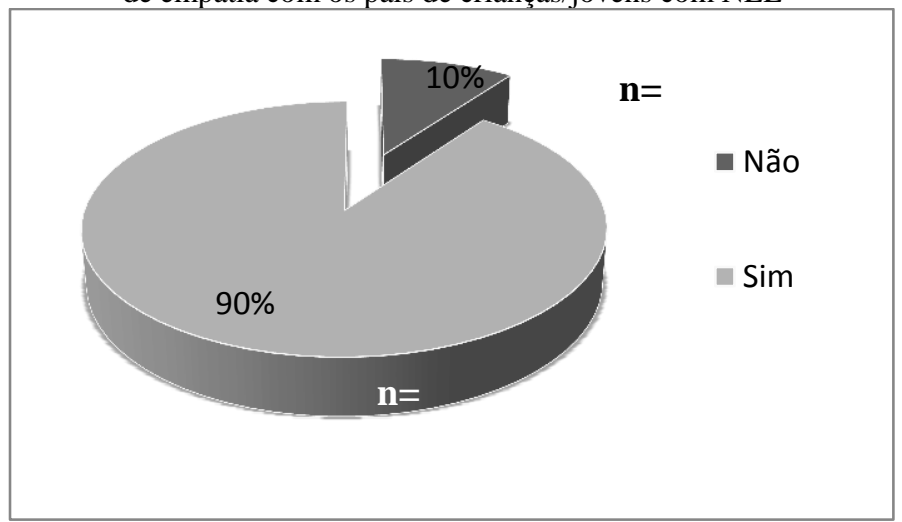

No gráfico I registou-se que quase todos os sujeitos da amostra corroboram com o facto de a $\mathrm{CNV}$ contribuir para uma relação 
interpessoal de empatia com os pais de crianças/jovens com NEE $(n=18$; $90 \%)$.

\section{DISCUSSÃO DOS RESULTADOS}

Analisando os dados da nossa investigação, aplicada a 20 professores de educação especial, podemos concluir que a CNV constitui um dos elementos fundamentais para um estabelecimento de relações de parceria no trabalho a desenvolver com pais de crianças/jovens com NEE. As estratégias básicas para melhorar a comunicação entre família e profissionais passam por uma atitude de respeito e confiança, elementos considerados essenciais para uma comunicação produtiva e afetiva (McWilliam, 2003; Pimentel, 2005; Sousa, 2005; Correia, 2008). O trabalho do profissional de educação especial com as famílias envolve, não só um conhecimento prévio e profundo acerca dos modelos teóricos em que assenta a dinâmica familiar, bem como as características das famílias de crianças/jovens com NEE e um conjunto de aptidões importantes dos profissionais no que respeita à comunicação (Correia, 2008).

Procurou-se saber a opinião dos participantes acerca do funcionamento das estratégias de comunicação para estabelecer uma relação empática com os pais, o que se constitui como categoria, da qual emergiram 9 subcategorias, sendo as mais significativas "Deixar os pais expressarem-se livremente" ( $\mathrm{n}=7 ; 23 \%)$; a "Escuta ativa" ( $\mathrm{n}=7 ; 23 \%)$; o "Conhecimento da problemática dos alunos com NEE" $(n=4 ; 13 \%)$ e o "Mostrar interesse pela problemática dos alunos com NEE" $(\mathrm{n}=4 ; 13 \%)$. Estas respostas (cf. quadro n. ${ }^{\circ}$ 1) consubstanciam os resultados anteriormente expostos. Por outro lado, enfatizam a importância que os professores atribuem à $\mathrm{CNV}$, aquando do contacto direto com os pais de crianças/jovens com NEE.

Neste âmbito há a salientar que estes pais, por norma, deparam-se com vários desafios complexos. O nascimento de membro familiar com uma problemática, sobretudo se esta é severa, provoca um grande impacto na família e nas suas transições ecológicas, resultando, na maioria dos casos, numa expressão de revolta, recusa, intensa ansiedade e até frustração (Correia, 2003).

$\mathrm{O}$ processo educativo de uma criança/jovem depende, fundamentalmente, dos seus pais e dos seus professores. Daí a importância de uma aliança comum entre ambos. A função mais importante dos professores consiste em apoiar e formar os pais para conseguir a máxima participação ativa dos mesmos no processo pedagógico e terapêutico do seu filho, o que implica um processo 
comunicacional assertivo e empático (Alarcão, 2000; MacWilliam, 2003; Correia, 2008).

Não só todo o processo educativo é orientado para diminuir o défice e atenuar as consequências da incapacidade, como também para o devido apoio continuado aos pais para o desenvolvimento do seu filho com NEE (Correia, 2003, 2008; Leitão, 2007). A este propósito salienta-se que a comunicação interpessoal entre os professores e os pais de crianças/jovens com NEE é um importante meio através do qual a informação é trocada e entendida por esta díade, facultando-se a livre expressão de sentimentos e dúvidas por parte dos pais (McWilliam, 2003; Cruz, 2005; Correia, 2008; Goleman, 2010).

É através da comunicação interpessoal que se criam as relações sociais, pois toda a interação tem um sentido emocional implícito. Falar com outra pessoa é um processo dinâmico, na medida em que quando se comunica, a outra pessoa reage e a sua reação influencia as nossas reações subsequentes (Goleman, 2010).

Quanto aos sistemas de CNV, apurou-se que, na amostra em estudo, quase todos os docentes demonstraram conhecer uma variedade dos mesmos (cf. quadro n. ${ }^{\circ}$ 2), sendo os mais citados pelos inquiridos os seguintes: a expressão facial, o contacto visual, ambos com o mesmo número de respostas $(\mathrm{n}=19 ; 16 \%)$. Depois surgem os gestos $(\mathrm{n}=16 ; 14 \%)$; a postura $(\mathrm{n}=15 ; 13 \%)$; o sorriso $(\mathrm{n}=13 ; 11 \%)$, a paralinguagem $(\mathrm{n}=12$; $10 \%)$; a cinésica $(\mathrm{n}=10 ; 9 \%)$; o tato $(\mathrm{n}=6 ; 5 \%)$; a aparência física $(\mathrm{n}=5$; $4 \%)$; a proxêmica $(\mathrm{n}=4 ; 3 \%)$. Salienta-se que os sistemas de CNV abarcam uma multiplicidade de estratégias que permitem o estabelecimento de comunicação entre o professor e os pais de crianças/jovens com NEE, tão indispensáveis para a criação de uma relação empática e, por conseguinte, para que haja uma cultura de parceria entre esta díade, resultando num apoio muito mais efetivo no processo educativo dos educandos (McWilliam, 2003; Pimentel, 2005; Sousa, 2005; Correia, 2008; Burgoon et al., 2010; Goleman, 2010).

Neste contexto, refere-se que, para Burgoon e colaboradores (2010), uma parte fundamental da competência comunicativa são os sistemas de CNV. Estes abarcam todos os signos e sistemas de signos não linguísticos que as pessoas usam para comunicarem (Knapp \& Hall, 2007; Ivy \& Wahl, 2009; Burgoon et al., 2010; Richmond et al., 2011).

O recurso a estes sistemas de comunicação é de extrema importância na relação e comunicação estabelecida entre o professor e os pais, na medida em que facilitam uma boa relação interpessoal, através da qual se pode criar no outro, neste caso os pais, a disponibilidade para aceitar a problemática do seu educando e as suas dificuldades, exprimindo os seus sentimentos negativos (medo, angústia, agressividade, tristeza, entre outros). Por exemplo, a redução da distância equivale a 
uma relação de aceitação e respeito mútuo, estabelecida entre duas pessoas, em que uma está vulnerável, experienciando emoções negativas (tristeza, ansiedade, medo) e a outra é capaz de escutar, aceitar e, se possível, ajudar numa atitude de disponibilidade e tolerância (McWilliam, 2003; Pimentel, 2005; Sousa, 2005; Correia, 2008; Burgoon et al., 2010; Goleman, 2010; Richmond et al., 2011).

É interessante constatar que dos sistemas de CNV que os inquiridos mais valorizaram foram a expressão facial, o olhar e a postura (cf. quadro n. ${ }^{\circ}$ 2). O olhar é assumidamente um sistema de comunicação que imprime ao ato comunicativo mais envolvimento, mais atenção, maior proximidade, mais partilha, enfim bastante mais comunicação (arriscarnos-íamos a dizer). Da cinésica fazem parte tês grandes subsistemas de CNV: a expressão facial, a postura e o movimento corporal (Knapp \& Hall, 2007; Richmond et al., 2011). Assim, não é difícil perceber que é um sistema bastante expressivo, daí o usarmos de uma forma mais involuntária e inconsciente, no entanto, poderá tornar-se mais expressivo quando usado de forma premeditada e propositada. Talvez por estas razões estes tenham sido os sistemas de CNV mais valorizados pelos inquiridos.

Por outro lado, o tato e a proxêmica foram claramente os dois sistemas de CNV que os inquiridos menos valorizaram (cf. quadro n. ${ }^{\circ}$ 2). No que diz respeito ao tato, talvez porque em geral o associamos a situações de maior intimidade, este não foi muito referido. No entanto, se usado de uma forma assertiva, é um sistema de comunicação potenciador de grande empatia e inclusão (Knapp \& Hall, 2007; Damásio, 2010; Goleman, 2010; Magalhães, 2011; Richmond et al., 2011). No que diz respeito à proxêmica, parece-nos que é um sistema pouco trabalhado e para o qual somos pouco alertados, o que implica que as suas potencialidade acabem por não ser valorizadas. Mormente, não deixa de ser um sistema do qual nos servimos com diferentes intuitos: a distância que mantemos relativamente aos outros mostra o tipo de relação que pretendemos manter e que sentimentos nutrimos por eles; por sua vez, a forma como organizamos o nosso espaço diz muito sobre a nossa personalidade e sobre a fase da vida em que nos encontramos, entre outros (Hall, 1986; Driver, 2010; Goman, 2010; Richmond et al., 2011).

Assim, apesar de usarmos o espaço constantemente e de forma espontânea, somos pouco levados a refletir sobre ele na relação que estabelecemos com os outros. Talvez tenha sido por isso que a maioria dos inquiridos tenha desvalorizado este sistema de CNV.

No que se refere à importância atribuída pelos sujeitos da amostra aos sinais não-verbais que os pais de crianças/jovens com NEE emitem, verificou-se que a maioria $(\mathrm{n}=10 ; 50 \%)$ atribui muita importância; 
seguidos dos professores que admitiram que o fazem alguma importância $(\mathrm{n}=6 ; 30 \%)$. Apenas um docente diz que tem toda a importância $(\mathrm{n}=1$; $5 \%$ ). Estes dados (cf. quadro n. ${ }^{\circ} 3$ ) levam a considerar que todos os professores deveriam estar mais atentos aos sinais não-verbais emitidos pelos pais de crianças/jovens com NEE, tendo-se em conta que todo o ato humano é comunicação. Como é defendido pela Escola de Palo Alto (Watzlawick et al., 2007), todo o comportamento pode ser considerado comunicação e toda a comunicação pode ser considerada comportamento. Todos os processos de comunicação, quaisquer que sejam, implicam sempre dois registos: o conteúdo e a relação (Knapp \& Hall, 2007; Goleman, 2010; Richmond et al., 2011). Por outras palavras, toda a intervenção humana tem sempre subjacente a transmissão de informação, mas, simultaneamente, uma orientação sobre a forma como a informação deve ser interpretada. As interações humanas estão condicionadas pela pontuação das sequências comunicacionais que se efetuam no decorrer de uma relação. O Homem tem a possibilidade de comunicar e de se relacionar com os outros por duas vias diferentes, mas complementares: a digital e a analógica (Watzlawick et al., 2007). Por fim, todas as trocas interacionais entre as pessoas obedecem ao princípio da simetria e da complementaridade, ou seja, a relação simétrica prevê a minimização da igualdade da diferença; a complementar tem por base a maximização da diferença (Watzlawick et al., 2007; Mucchielli, 2009).

Assim, a relação comunicacional estabelecida entre os professores e os pais deve ocorrer efetivamente numa abordagem holística das interações que se estabelecem entre estes atores, que muito contribuem para o sucesso de inclusão dos alunos com NEE e um sistema educativo com mais qualidade.

Relativamente aos sinais não-verbais mais comuns emitidos pelos pais de crianças/jovens com NEE e percecionados pelos docentes de educação especial, destacamos a expressão facial $(\mathrm{n}=16 ; 20 \%)$, seguida dos gestos e do contacto visual com percentagens idênticas $(\mathrm{n}=13 ; 17 \%)$, a postura $(\mathrm{n}=12 ; 15 \%)$, a paralinguagem $(\mathrm{n}=10 ; 13 \%)$, o sorriso $(\mathrm{n}=7 ; 9 \%)$ e a cinésica $(n=5 ; 6 \%)$. Um dos inquiridos valorizou a aparência física $(n=1$; $1 \%$ ) e nenhum atribui importância ao tato, assim como à proxêmica (cf. quadro n. $\left.{ }^{\circ} 4\right)$.

Mais uma vez, à semelhança da questão sobre os sistemas de CNV que os docentes conhecem (cf. quadro $\mathrm{n}^{\circ}{ }^{\circ}$ 2) revelam aqui, também, estarem atentos aos mesmos, quando emitidos pelos pais de crianças/jovens com NEE, elegendo a expressão facial como o sinal nãoverbal mais utilizado por estes. De novo, à semelhança das convicções expressas acima pelos inquiridos, verificamos que tanto o tato como a proxêmica não são utilizados por estes pais, possivelmente pelas mesmas razões que já atrás referimos. 
Através dos resultados, apurou-se que à categoria "Sinais não-verbais influenciadores da relação estabelecida com crianças/jovens", emergiram 7 subcategorias, das quais sobressaíram as seguintes: a "Postura" $(\mathrm{n}=13$; $28 \%)$; o "Contacto visual" ( $(\mathrm{n}=11 ; 24 \%)$; a "Expressão facial" ( $\mathrm{n}=7$; $15 \%)$; o "Sorriso" $(\mathrm{n}=7 ; 15 \%)$ e "Os gestos" ( $\mathrm{n}=4 ; 9 \%)$. O recurso a estes sinais, por parte dos professores inquiridos (cf. quadro n. ${ }^{\circ}$ 5), demonstra que os mesmos estão implicados na relação de ajuda que têm de assumir face aos pais de crianças/jovens com NEE, sendo esta uma forma de otimizar o processo inclusivo dos seus educandos, bem como dar espaço aos pais para expressarem os seus sentimentos, as suas dificuldades e as suas dúvidas.

O nascimento de uma criança com NEE, por si, já acarreta alterações importantes nos diferentes subsistemas da família. Altera-se, em muitos casos, a rotina diária do casal, surgem alterações profissionais, relacionais e económicas. Quando o nascimento implica a chegada de uma criança especial, Gronita e colaboradores (2009) referem que se está face a um fator acrescido de stress na família. As situações de risco são potencializadas, tornando a família mais vulnerável, pois terá de se ajustar e adaptar ao desconhecido.

Este é um processo com consequentes fases que se verificam nas famílias ou nos seus membros, quando não chega o filho sonhado e, em vez dele, surge uma criança com NEE. Estes pais atravessam um período de luto, associado à perda do filho idealizado, resultando num um forte impacto emocional (Serrano \& Correia, 2003). Como tal, é importante que os professores recorram às mais variadas formas de comunicação, quer verbal, quer não-verbal, para poderem ajudar os pais nesta sua caminhada.

Procurou-se também saber qual a opinião dos professores acerca da forma como podem estimular a CNV com os pais de crianças/jovens com NEE. Assim, desta categoria apuraram-se 7 subcategorias, sendo as mais significativas as seguintes: "Depende da pessoa em questão", "Olhá-los nos olhos"; "Estabelecer uma aproximação física", todas com o mesmo número de resposta $(\mathrm{n}=6 ; 21 \%)$. Há a considerar a opinião de dois sujeitos da amostra, os quais referiram o sorrir para os pais de crianças/jovens com NEE uma forma de estimular a CNV $(n=2 ; 7 \%)$. Uma vez mais, os dados apurados (cf. quadro n. ${ }^{\circ} 6$ ) estão em consonância com os anteriores, demonstrando-se que há professores que se preocupam em reduzir a distância, olhando nos olhos os pais, o que revela uma atitude de compreensão e de confiança (Ambadar et al., 2009).

McWilliam (2003) considera que a participação dos pais é fundamental no trabalho a ser desenvolvido com os seus filhos com NEE, aconselhando, por isso, que estes e os professores constituam uma equipa 
de parceria, quer nos momentos de avaliação quer na planificação da intervenção e avaliação da sua eficácia. Esta dinâmica de trabalho vai promover a autoestima e autoconfiança dos pais e (re)conhecer os pontos fortes do educando, de modo a levar a cabo a intervenção, com um objetivo comum: a promoção do desenvolvimento e bem-estar do aluno e ao restabelecimento da organização familiar (McWilliam, 2003; Pereira, 2002).

Mormente o exposto registou-se que quase todos os sujeitos da amostra corroboram com o facto de a CNV contribuir para uma relação interpessoal de empatia com os pais de crianças/jovens com NEE $(n=18$; $90 \%$ ). Estes resultados (cf. gráfico $\mathrm{n}^{\circ}{ }^{\mathrm{o}} 1$ ) confirmam o anteriormente dito, inclusive, a relação de ajuda é um elemento de competência do professor, sobretudo de educação especial, ou seja, um instrumento válido que este profissional dispõe no estabelecimento de uma comunicação empática, objetiva e orientada com estes pais (Correia, 2008).

Recorde-se, a importância que a CNV tem no processo comunicacional entre professor/pais, na procura das suas necessidades, expetativas e desejos, para que se possa estabelecer uma cooperação entre estes agentes educativos, sempre ancorada no desenvolvimento de uma relação de confiança (McWilliam, 2003).

É incontestável que a comunicação é basilar para qualquer ser humano. Como tal, o domínio da comunicação interpessoal, pelas suas características, é determinante, principalmente na relação entre o professor de educação especial e os pais de crianças/jovens com NEE. Assim, no contexto da relação de atendimento, os professores e os pais devem interagir sob influência da realidade de cada um. Corroborando com estas premissas, Correia (2008) afirma que toda a relação existente no atendimento aos pais de crianças/jovens com NEE depende, grosso modo, das capacidades comunicativas dominadas pelo professor, onde não se deve escurar os sistemas de CNV.

Na opinião de Goleman (2010), a sincronia entre emissor e recetor possibilita-lhes deslizar numa dança não-verbal, uma vez que ambos devem ser capazes de ler instantaneamente sinais não-verbais e agir. $\mathrm{O}$ mesmo autor acrescenta que a ausência desta capacidade deteriora qualquer competência social, anulando as interações, enquanto o seu domínio gera uma grande ressonância emocional. Sendo a CNV um sistema de comunicação riquíssimo e claramente privilegiado, tiraríamos muito mais partido dele se aprendêssemos a utilizar alguns dos seus sinais voluntariamente. Tornar-nos-íamos mais expressivos, claros e autênticos.

Em suma, quanto maior for a ênfase dada por esta díade nos processos comunicacionais, verbais e não-verbais, maior será o efeito do suporte no seu bem-estar. Desta forma, o entendimento da criança/jovem com NEE e dos seus pais não poderá excluir toda a dimensão social, nomeadamente o 
conhecimento e capacidade de analisar toda a situação, para que, identificando a sua forma organizativa, se possam desenvolver estratégias de intervenção eficazes e adequadas aos educandos e aos pais.

\section{CONCLUSÃO}

Este estudo desenhou-se a partir da crença na valorização da CNV e do desafio de querer compreender de que forma esta se afirma na construção de uma relação interpessoal entre o professor de educação especial e os pais de crianças/jovens com NEE. Por conseguinte, o papel do professor de educação especial é o de ser mediador entre a escola, a família, o aluno com NEE e a sociedade, transformando-se num agente indispensável na socialização e inclusão destes (Sousa, 2005; Correia, 2008; Rodrigues, 2011).

No contexto da filosofia da escola inclusiva, compete à mesma ser a primeira a estabelecer a comunicação com os pais de crianças/jovens, cujo envolvimento, na opinião de Marques (2000), passa pela comunicação pais/filhos, pais/professores. A valência desta relação assenta na sua importância imensurável para a vida dos agentes interatuantes. Assim, a cúpula do envolvimento dos pais na vida escolar dos seus filhos passa pelo estabelecimento de uma comunicação eficaz. Neste sentido, aos professores de educação especial compete a promoção da comunicação com os pais, visando uma cooperação recíproca, na medida em que a esta permite a participação das famílias na escola e, consequentemente, um maior envolvimento das famílias na educação dos seus filhos (Correia, 2008).

Concluiu-se também que a CNV deve ser uma das competências dos professores, a qual pode ser demonstrada pelo valor da escuta ativa, na medida em que se trata de uma comunicação em que o professor ou os pais comunicam o seu interesse uns pelos outros.

Assim, através do estudo empírico, de natureza quantitativo e qualitativo, verificámos na amostra analisada que, na generalidade, os professores de educação especial têm uma opinião favorável face à construção de relações interpessoais com os pais de crianças/jovens com NEE, preocupando-se por construir uma relação interpessoal. Na maioria, os participantes no estudo revelaram conhecimentos sobre os principais sistemas da $\mathrm{CNV}$, recorrendo à linguagem corporal, à proxêmica, à escuta ativa, ao olhar nos olhos, entre outras, como importantes na construção de uma relação interpessoal com os pais de crianças/jovens NEE. Concluiuse também que a maioria dos professores valoriza e interpreta a CNV da parte dos pais, como forma de estabelecerem uma comunicação empática, onde prime a confiança e o respeito mútuo. Foi igualmente considerado, 
por parte de todos os professores participantes, que deve ser dado aos pais a possibilidade de estes poderem expressar os seus sentimentos, o que deve implicar saber interpretar os sinais não-verbais emitidos pelos mesmos.

Considera-se muito gratificante a realização desta investigação, muito embora o tema não se esgote aqui, pelo que se espera que o mesmo sirva de motivo para a realização de outras investigações, uma vez que se considera que os professores necessitam de aperfeiçoar algumas características latentes em si. Estas não se referem apenas ao grau de conhecimentos que eles possam ter, mas também à agilidade e diplomacia para poder lidar com estes pais, as quais devem ser tidas numa visão holística.

\section{BIBLIOGRAFIA}

Afonso, N. (2005). Investigação Naturalista em Educação - Um Guia Prático Prático e Crítico. Porto: ASA Editores, S.A.

Alarcão, M. (2000). (Des) Equilíbrios Familiares. Coimbra: Quarteto Editora.

Almeida, J. (2008). Dimensões Comunicativas no Ensino de Línguas. (5 Ed.). Campinas: Pontes Editores.

Alves, M. (2009). Intervenção Precoce e Educação Especial. Práticas de Intervenção Centradas na Família. Viseu: Psico \& Soma.

Ambadar, Z., Cohn, J., \& Reed, L. (2009). All Smiles are Created Equal: Morphology and Timing of Smiles Perceived as Amused, Polite, and Embarrassed/Nervous. Journal of Nonverbal Communication, 33(1), 17-34.

Antunes, C. (2003). Relações Interpessoais e Autoestima. Petrópolis: Vozes.

Axtell, R. (2007). Essential Do's and Taboos: The complete Guide to International Business and Leisure Travel. New York: Wiley.

Bardin, L. (2011). Análise de Conteúdo. 4. ${ }^{\mathrm{a}}$ Ed. Lisboa: Edições 70.

Burgoon, J., Guerrero, L., \& Floyd, K. (2010). Nonverbal Communication. $\left(2^{\text {nd }}\right.$ Ed.). Boston: Allyn \& Bacon.

Correia, L. (2003). O sistema Educativo Português e as Necessidades Educativas Especiais ou Quando a Inclusão quer Dizer Exclusão. In L. Correia (Org.), Educação Especial e Inclusão: Quem Disser que Uma Sobrevive sem a Outra Não Está no seu Perfeito Juízo (pp.1139). Porto: Porto Editora.

Correia, L. (2008). Inclusão e Necessidades Educativas Especiais. Um Guia para Educadores e Professores. Porto: Porto Editora.

Cruz, O. (2005). Parentalidade. Coimbra: Edições Quarteto. 
Damásio, A. (2010). O Livro da Consciência: A Construção do Cérebro Consciente. Maia: Círculo de Leitores.

Davis, F. (1979). A Comunicação Não-Verbal. São Paulo: Summus Editorial.

Dias, M. (2009). O Vocabulário do Desenho de Investigação - A Lógica do Processo em Ciências Sociais. Viseu: Psico \& Soma.

Dortier, J. (2001). Le langage: Nature, Histoire et Usage: Les Théories Linguistiques, Les Débats, les Origines, les Enjeux. Paris: Éditions Sciences Humaines.

Driver, J. (2010). Como Observar as Pessoas - Dizemos Mais do que Pensamos. Um plano para Conseguir Tudo o que Quer com a Nova Linguagem Corporal. Lisboa: Editorial Bizâncio.

Dunst, C., \& Dempsey, I. (2007). Family/ Professional Partnerships and Parenting Competence, Confidence and Enjoyment. International Journal of Disability, Development and Education, 54, 305-318.

Fritzen, J. (1987). Relações Humanas Interpessoais. Petrópolis, RJ: Vozes.

Gabin, F., \& Dortier, J. (2008). La Communication. État des Savoirs. $\left(3^{\mathrm{e}}\right.$ éd. Actualisée). Paris : Éditions Sciences humaines. Consultado a $11 / 02 / 12$

em http://communication.revues.org/index 1923.html\#tocto1n2.

Goleman, D. (2010). Inteligência Emocional. (15ª Ed.). Lisboa: Círculo de Leitores.

Goman, C. (2010). A Vantagem Não-Verbal. Petrópolis: Editora Vozes.

Gronita, J., Pimentel, J., Matos, C., Bernardo, A., \& Marques, J. (2009). Os Nossos Filhos são Diferentes: Como Podem os Pais Lidar Com Uma Criança Com Deficiência. Lisboa: Fundação Calouste Gulbenkian. Consultado a $11 / 02 / 12$ em http://www.gulbenkian.pt/media/files/fundacao/programas/PG\%20D esenvolvimento\%20Humano/pdf/Os_nossos_filhos_s__o..._diferent es.pdf.

Hall, E. (1986). A Dimensão Oculta. Lisboa: Relógio d'Água.

Ivy, D., \& Wahl, S. (2009). The Nonverbal Self: Communication for a Lifetime. Boston: Allyn \& Bacon.

Knapp, M., \& Hall, J. (2007). Nonverbal Communication in Human Interaction. $\left(7^{\text {th }}\right.$ Ed.). Boston: Wadsworth/ Cengage.

Leathers, D., \& Eaves, M. (2008). Successful Nonverbal Communication: Principles and Applications ( $4^{\text {th }}$ Ed.). Boston: Allyn \& Bacon.

Leitão, M. (2007). Inclusão de Alunos com Necessidades Educativas Especiais. Tese de doutoramento não publicada. Universidade dos Açores. 
Magalhães, A. (2011). O Código de Ekman: o Cérebro, a Face e a Emoção. Porto: Edições Universidade Fernando Pessoa.

Manusov, V., \& Patterson, M. (2005). The Sage Handbook of Nonverbal Communication. Thousand Oaks, CA: Sage Publications.

Marques, M. (2000). O Partenariado na Escola. Lisboa: Instituto de Inovação.

McWilliam, P. (2003). Estratégias Práticas para a Intervenção Precoce Centrada na Família. Porto: Porto Editora.

Moore, N., Hickson, M., \& Sacks, D. (2010). Nonverbal Communication: Studies and Applications. ( ${ }^{\text {th }}$ Ed.). New York: Oxford University Press.

Mucchielli, A. (2009). Influencer, Persuader, Motiver: De Nouvelles Techniques. Paris : Armand Colin.

Pereira, F. (2002). Caminhos e Processos com Alguns Sucessos. Oliveira de Frades: ASSOL.

Pereira, A., \& Serrano, A. (2010). Abordagem Centrada na Família em Intervenção Precoce: Perspetiva Histórica, Concetual e Empírica. Diversidades, 4-11.

Pimentel, J. (2005). Intervenção Focada na Família: Desejo ou Realidade - Perceções de Pais e Profissionais sobre as Práticas de Apoio Precoce a Crianças com Necessidades Educativas Especiais e suas Famílias. Lisboa: Secretariado Nacional para a Reabilitação e Integração da Pessoa com Deficiência.

Quivy, R., \& Campenhoudt, L. (2003). Manual de Investigação em Ciências Sociais ( $3^{\mathrm{a}}$ Ed.). Lisboa: Gradiva.

Richmond, V., MaCroskey, J., \& Hickson, M. (2011). Nonverbal Communication. Nonverbal Behaviour in Interpersonal Relations. ( $7^{\text {th }}$ Ed.). Boston: Allyn \& Bacon.

Rodrigues, D. (2006). Notas sobre Investigação em Educação Inclusiva. In D. Rodrigues (Ed.), Investigação em Educação Inclusiva (pp.1116). Lisboa: Faculdade de Motricidade Humana.

Rodrigues, D. (2011). O Paradigma da Educação Inclusiva: Reflexões sobre uma Agenda Possível. Revista Inclusão, 1, 7-13.

Serrano, A., \& Correia, L. (2003). Parcerias Pais-Profissionais na Educação da Criança com NEE. In Correia, L., Inclusão $e$ Necessidades Educativas Especiais: Um Guia para Educadores e Professores (pp. 61-66). Porto: Porto Editora.

Sousa, F. (2005). A Participação dos Pais na Escola. Revista Sonhar, 1 (1), 75-97.

Tuckman, B. (2002). Manual de Investigação em Educação - Como Conceber e Realizar o Processo de Investigação em Educação. 2. ${ }^{a}$ Ed. Lisboa: Calouste Gulbenkian. 
Vaz Freixo, M. (2011). Metodologia Científica: Fundamentos, Métodos e Técnicas. 3. ${ }^{a}$ Ed. Lisboa: Instituto Piaget.

Watzlawick, P., Beavin, \& J. Jackson, D. (2007). Pragmática da Comunicação Humana. 16ª Ed. São Paulo: Editora Cultrix. 